\title{
Anterior crossbite correction in early mixed dentition stage using functional jaw orthopedics principles: a case report with two-years follow-up
}

\author{
Fabiana Monte Callado ${ }^{1}$, Maria Luiza Sperandeo ${ }^{2}$ \\ ${ }^{1}$ School of Dentistry, Faculdade de Conchas, Conchas, São Paulo, Brazil \\ ${ }^{2}$ Department of Physiology, Universidade Estadual de Campinas, Campinas, São Paulo, Brazil \\ ${ }^{1}$ Corresponding author \\ E-mail: ${ }^{1}$ fabianacallado@yahoo.com.br, ${ }^{2}$ odontologia.sperandeo@yahoo.com.br
}

Received 9 August 2021; received in revised form 20 September 2021; accepted 3 November 2021 DOI https://doi.org/10.21595/jfocg.2021.22173

Check for updates

Copyright $(02021$ Fabiana Monte Callado, et al. This is an open access article distributed under the Creative Commons Attribution License, which permits unrestricted use, distribution, and reproduction in any medium, provided the original work is properly cited.

\begin{abstract}
A five-year-old and four-month-old male patient presented with Class I malocclusion, anterior crossbite (pseudo-class III) with an overbite, midline deviation to the left $(5 \mathrm{~mm})$, left unilateral chewing preference, and incisors in bi-retrusion with diastemas. Initial Bimler cephalometry showed negative anterior face angle $(<A)$, negative bone overjet (A'B'), mesoprosope biotype, negative suborbital facial index, microrhinic dysplasia, and reduced T-TM distance. Pre-treatment gnathostatic models revealed vertical asymmetry and increased left occlusal plane. After the initial assessment, we initiated the treatment with resin-composite planas direct tracks in the deciduous upper molar surface to lift the bite. The patient was oriented to perform right-side mastication movements using hyperboloid exercises. After one month, a new resin-composite lift was carried out in the lower deciduous molar occlusion surface. Planas direct tracks were built directly on the occlusal of the maxillary molars 64 and 65 to start centering the patient's midline, which was deviated to the left, raising the bite, and increasing the vertical dimension. In the same dental appointment, we completed the right side on the occlusal of the teeth 54 and 55, to adjust the occlusion using 200 microns articulated paper. After a month, the patient returned to the dental office and resins were placed in the occlusal surface of teeth 74,75 , 84 , and 85, completing the direct planas tracks and leaving the occlusal plane the most parallel to the Camper's Plan. Direct planas tracks' adjustments were made throughout the patient's treatment returns, with 200 microns articulated paper and selective wear. Hyperboloid (silicone-made accessory to stimulate the stomatognathic system) was used to perform chewing exercises on the right side and instructed to be performed before the main meals, for five minutes, encouraging chewing on the right side. The subsequent masticatory evaluation showed protrusive movements. To reduce this movement, planas direct tracks from canine-to-canine were prepared, correcting the anterior bite, and reducing the midline deviation to the left. Posteriorly, functional orthopedic treatment began with the Simões Network 3 (SN3) device, with Bimler's upper dental arch not touching the incisors and an upper expander. Concomitantly, in the lower dental arch, we initiated the treatment with a Hawley dental appliance against the cervical third of lower incisors and a $\mathrm{W}$-shaped lingual retainer. The SN3 device was built in a laboratory specialized in maxillary functional orthopedics, after molding the patient with alginate and wax bite registration. After 12 months of treatment, the patient presented a centralized midline, had permanent lower incisors, erupting upper central incisors, and adequate bilateral chewing. After 24 months of treatment, the patient presented physiological limits with the contact of the upper central incisors in a determined area with $2 \mathrm{~mm}$ overjet, centralized midline, efficient bilateral chewing, and balanced maxillomandibular growth. Post-treatment Bimler cephalometry showed a negative anterior face angle $(<\mathrm{A})$, positive bone overjet (A'B'), mesoprosope biotype, increased T-TM distance. In addition, Planas' gnathostatic models evidenced a symmetric occlusal plane. In conclusion, functional jaw orthopedics approaches can significantly contribute to the inhibitory and excitatory stimulation of the mandible to the maxilla. Furthermore, functional orthopedics might establish an appropriate development of the stomatognathic system in patients with mixed dentition.
\end{abstract}


Keywords: functional jaw orthopedics, class I malocclusion, anterior crossbite.

\section{Introduction}

Recently, orthodontists have been constantly challenged to treat patients diagnosed with compromised skeletal Class III malocclusions, which regularly can be associated with maxillary retrognathism, mandibular prognathism, or a combination of these two sagittal skeletal discrepancies. However, Class III malocclusion due to maxillary deficiency is predominant in most cases, enabling adequate interventions through devices for maxillary protraction [1]. Class III malocclusion differential diagnosis is performed worldwide using functional, cephalometric, and clinical assessments [1]. While the functional evaluation verifies if there is an anterior trajectory of mandibular closure (that might aggravate the malocclusion), the cephalometric appraisal identifies the existence of maxillary retrusion, mandibular protrusion, or both [2]. As far as the clinical assessment is concerned, the specialist can analyze facial aesthetics features, considered one of the most relevant treatment outcomes [2]. Notably, the co-existence of anterior crossbite among individuals with Class III malocclusion rarely self-corrects and occurs due to a change in the buccolingual relationship of one or more anterior teeth, with the maxillary and mandibular incisors lingually and facially tilted, respectively.

The success of non-surgical treatment of Class III malocclusion often depends on the patient's age, growth pattern, dental compensation, and the severity of the malocclusion [3]. Furthermore, elements such as synergistic collaboration between parents and the patient regarding the adequate use of the indicated oral appliances and the involvement of bone structures are also associated with the prognosis of non-surgical intervention of Class III malocclusion [3]. Interceptive orthodontic treatment is defined as any procedure that eliminates or minimizes the severity of a developing malocclusion, the complexity of malocclusion, and correlated treatment time and costs [4], [5]. Additionally, the early mixed dentition interceptive treatment can correct the anterior crossbite, thus favoring balanced bone growth and, conceivably, preventing malocclusion during later life stages [6].

Jaw function orthopedics provides a morphological and functional improvement, stimulating normal facial growth and establishing better aesthetic outcomes [7]. Significant skeletal and dentoalveolar changes are commonly observed after treatment, primarily driven by maxillary advancement, clockwise mandible rotation, an increase in the convexity of the skeletal profile, and a decrease in the facial soft tissue angle [8]. Furthermore, a buccal inclination of the anterior upper teeth, a lingual inclination of the lower incisors, an increase in the mandibular plane angle, and an increase in the total and anteroinferior facial heights have been reported among treated individuals [8]. Over the last number of years, several treatment protocols have been described to correct the anterior crossbite in the mixed dentition [9]. Notwithstanding, it is still unclear whether specific protocols are more efficient than others. Hence, this clinical report describes a complete treatment procedure using a combination of planas direct tracks and lower winglets model (Simões Network 3 - SN3) for the anterior crossbite correction and centralization of the midline at the beginning of mixed dentition.

\section{Case description}

In May 2017, a five-year and four-month-old Brazilian male patient was presented at a private practice office for an intraoral clinical examination without any specific self- or parent-reported major complaint. The patient was referred to the orthodontics specialist because of anterior crossbite and chewing problems. Antenatal and postnatal history was unremarkable, and the patient's development was normal. He was in good general health, without any allergies or previous orthodontic treatment. The patient's mother emphasized that several specialists had already evaluated the patient, but none declared the possibility to deliver specific care at that age. An initial clinical and radiographic examination (based on lateral cephalometric teleradiographs 
and panoramic radiography) revealed dolichocephalic head, no apparent gross asymmetry, remarkable midline deviation to the left $(5 \mathrm{~mm})$, left unilateral chewing preference, incisors in bi-retrusion with diastemas, and Class I malocclusion (ANB $<-1^{\circ}$ ), anterior crossbite (pseudo-class III malocclusion) with an overbite (Fig. 1 and Table 1). Furthermore, the mandible was mesially positioned (negative overjet), and we observed a microrhinic dysplasia (rotational syndrome featured by the growth deficiency of the middle facial third). A complete initial cephalometric evaluation is presented in Table 1, column A. Table 2 (section A) displays the values of the anatomical structures related to the right and left sides on the initial assessment. The upper incisors were (proclined/retroclined), while the lower incisors were (vertical/horizontal). The primary aim of the defined treatment was to balance shape and stomatognathic function development. This treatment plan involved the use of planas direct tracks and the Bimler appliance. The patient's parents informed consent for the orthodontic treatment, the publication of registered images, and the case report's publication. No institutional review board analysis was needed to publish this case report. However, the informed consent form was obtained from the parents of all subjects.
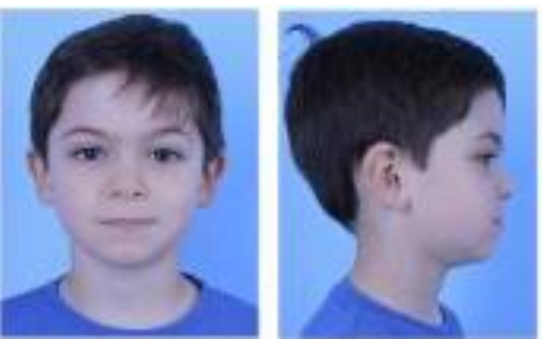

a)
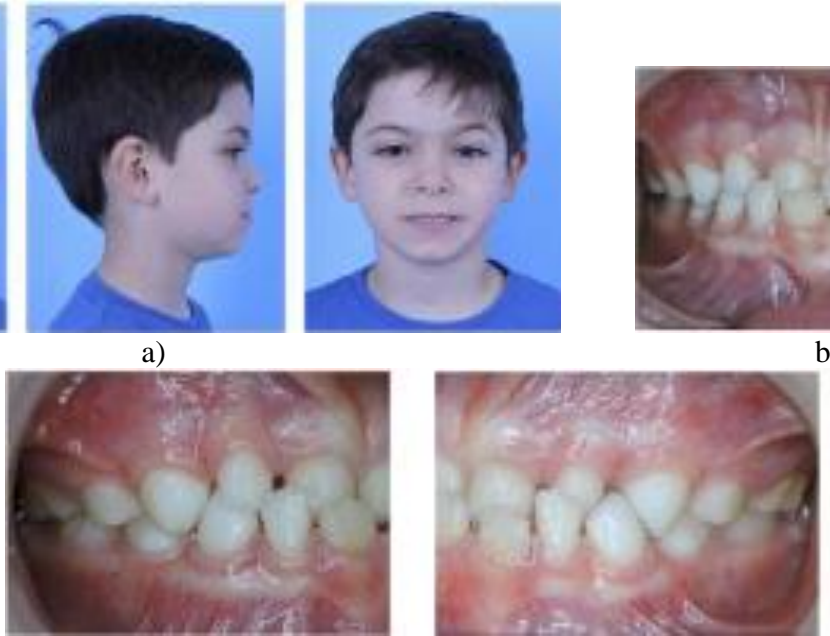

c)

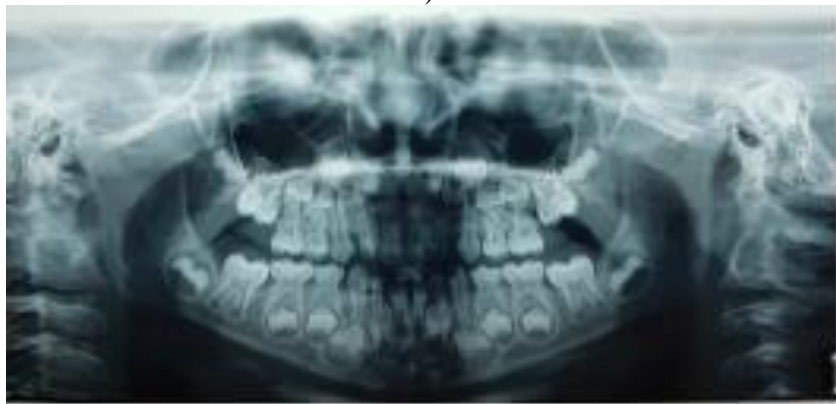

d)

Fig. 1. a) Extraoral photographs (T0), b) and c) intraoral photographs (T0), and d) orthopantomogram (T0); T0 refers to the pre-treatment stage 
Table 1. Bimler's cephalometric measures ( $\mathrm{T} 0$ - T1 - T2): T0 (initial assessment, pre-treatment, 2017), T1 (treatment progress, 2018), and T2 (post-treatment, 2019)

\begin{tabular}{|c|c|c|c|c|c|}
\hline Parameter & $\begin{array}{c}\text { Measured } \\
\text { value T0 } \\
\text { Column A }\end{array}$ & $\begin{array}{c}\text { Measured } \\
\text { value T1 } \\
\text { Column B } \\
\end{array}$ & $\begin{array}{c}\text { Measured } \\
\text { value T2 } \\
\text { Column C }\end{array}$ & $\Delta \mathrm{T} 0 / \mathrm{T} 2$ & $\begin{array}{l}\text { Normal } \\
\text { range }\end{array}$ \\
\hline \multicolumn{6}{|c|}{ Sagittal skeletal relationship $\left(^{\circ}\right)$} \\
\hline $\mathrm{N}-\mathrm{A}\left({ }^{\circ}\right)$ & 1.87 & -2.00 & 1.29 & -0.60 & \\
\hline $\mathrm{A}-\mathrm{B}\left({ }^{\circ}\right)$ & 3.00 & 2.00 & 4.23 & +1.23 & \\
\hline Mandibular Plane - Go-Me $\left(^{\circ}\right)$ & 21.78 & 27.85 & 21.45 & -0.33 & \\
\hline Palatal Plane - Ena-Emp $\left(^{\circ}\right)$ & -6.00 & -7.00 & -4.55 & +2.55 & \\
\hline Clivus Plane - Cls-Cli $\left({ }^{\circ}\right)$ & 64.92 & 63.47 & 64.50 & -0.42 & \\
\hline Stress Axys $-\mathrm{Cm}-\mathrm{Me}\left({ }^{\circ}\right)$ & Not available & Not available & Not available & $\begin{array}{c}\text { Not } \\
\text { available }\end{array}$ & \\
\hline Cranial Base - SN-FH $\left(^{\circ}\right)$ & 10.00 & -8.00 & 3.72 & -6.28 & \\
\hline C-Go $\left({ }^{\circ}\right)$ & -5.00 & -7.00 & Not available & $-2.00^{*}$ & \\
\hline \multicolumn{6}{|c|}{ Linear measures $(\mathrm{mm})$} \\
\hline Upper maxilla - A'-T & 48.60 & 53.06 & Not available & $+4.46^{*}$ & \\
\hline $\begin{array}{l}\text { Temporomandibular } \\
\text { position }-\mathrm{T}-\mathrm{Tm}\end{array}$ & 26.00 & 28.83 & Not available & $+2.83^{*}$ & \\
\hline Overjet - A'-B' & -2.02 & 1.00 & 3.61 & +5.63 & \\
\hline B'-Tm & 1.18 & 75.32 & 80.80 & +79.62 & \\
\hline Facial Depth - A'-Tm & 79.17 & 81.89 & 84.41 & +5.24 & \\
\hline Anterior Cranial Base - N-S & 70.05 & 79.47 & 74.48 & +4.43 & \\
\hline Sella Height - S-FH & 17.37 & 23.51 & 24.34 & +6.97 & \\
\hline Co-Go & 52.58 & 58.28 & 67.92 & +15.34 & \\
\hline Nasion Height - N-FH & 28.05 & 26.90 & 29.18 & +1.13 & \\
\hline $\mathrm{N}-\mathrm{M}$ & 105.41 & 113.30 & 118.29 & +12.88 & \\
\hline Alveolar Height & Not available & Not available & Not available & $\begin{array}{c}\text { Not } \\
\text { available }\end{array}$ & \\
\hline \multicolumn{6}{|c|}{ Angular analysis of skeletal profile } \\
\hline Profile angle $(1+2)$ & -1.13 & 1.60 & 5.52 & +6.65 & \\
\hline $\begin{array}{c}\text { Suborbital Facial } \\
\text { Height - FH-M }\end{array}$ & 77.35 & 86.40 & 89.11 & +11.76 & \\
\hline FH-M - A'TM & Not available & Not available & Not available & $\begin{array}{c}\text { Not } \\
\text { available }\end{array}$ & \\
\hline $\begin{array}{c}\text { Suborbital Facial Index - } \\
\text { A'TM-A'M }\end{array}$ & Not available & Not available & Not available & $\begin{array}{c}\text { Not } \\
\text { available }\end{array}$ & \\
\hline Upper basal angle & 60.41 & 60.33 & 59.95 & -0.46 & \\
\hline Lower basal angle & 26.29 & 30.99 & 26.00 & -0.29 & \\
\hline Total basal angle & 86.70 & 91.32 & 85.95 & -0.75 & \\
\hline \multicolumn{6}{|c|}{ Dental-skeletal analysis } \\
\hline Upper incisor angle & 107.54 & 106.95 & 117.68 & +10.41 & \\
\hline Interincisal angle & 144.54 & 137.25 & 132.61 & -11.93 & \\
\hline Lower incisor angle & 115.00 & 117.80 & 109.71 & -5.29 & \\
\hline Gonial angle & 118.00 & 122.45 & 121.40 & +3.4 & \\
\hline $\begin{array}{c}\text { Effective Mandibular } \\
\text { Length - Gn-Co }\end{array}$ & 110.38 & 117.99 & 122.49 & +12.11 & \\
\hline $\begin{array}{l}\text { Anteroposterior Dysplasia } \\
\text { Indicator }\end{array}$ & 86.52 & 81.19 & 88.27 & +1.75 & \\
\hline Overbite Depth Indicator & 60.71 & 66.96 & 68.24 & +7.53 & \\
\hline
\end{tabular}


Table 2. Anatomical structures identified during the initial (T0), intermediate (T1), and post-treatment panoramic radiographs

\begin{tabular}{|c|c|c|c|c|c|c|}
\hline & \multicolumn{2}{|c|}{$\begin{array}{c}\text { Initial assessment } \\
\text { Section A }\end{array}$} & \multicolumn{2}{c|}{$\begin{array}{c}\text { Intermediate assessment } \\
(\mathrm{mm}) \\
\text { Section B }\end{array}$} & \multicolumn{2}{c|}{$\begin{array}{c}\text { Final assessment } \\
(\mathrm{mm}) \\
\text { Section C }\end{array}$} \\
\hline Anatomical structure & $\begin{array}{c}\text { Left } \\
\text { Side }\end{array}$ & $\begin{array}{c}\text { Right } \\
\text { Side }\end{array}$ & Left Side & Right Side & $\begin{array}{c}\text { Left } \\
\text { Side }\end{array}$ & $\begin{array}{c}\text { Right } \\
\text { Side }\end{array}$ \\
\hline Condyle height & 9 & 9 & 11 & 15 & 9 & 9 \\
\hline Condyle width & 9 & 10 & 12 & 14 & 10 & 10 \\
\hline Mandible ramus height & 40 & 41 & 43 & 45 & 38 & 38 \\
\hline Mandible ramus width & 24 & 23 & 24 & 26 & 24 & 23 \\
\hline Mandible body height & 20 & 22 & 21 & 22 & 23 & 24 \\
\hline Mandible body width & 57 & 60 & 60 & 70 & 56 & 56 \\
\hline \multicolumn{2}{|l|}{ Articular eminence } \\
angle
\end{tabular}

After six months since the initial clinical appointment, the first gnathostatic model was created using the facial arch (Fig. 2). We decided to wait this time mainly because the patient could not adequately tolerate the dental tray in his mouth. As far as the gnasthostatic model is concerned, in the vertical direction, we observed a more significant maxillary intrusion on the left side, and transversally, the right maxilla side was larger than the left side. Thereafter, the planas direct tracks were placed in the occlusal surface of the upper and lower deciduous molars lifting the bite with incisors disoccluded (Fig. 3). Resin-composite was used to manage Class III molar occlusion, and the patient and parents were oriented to actively chew to the right side (through hyperboloid exercises).

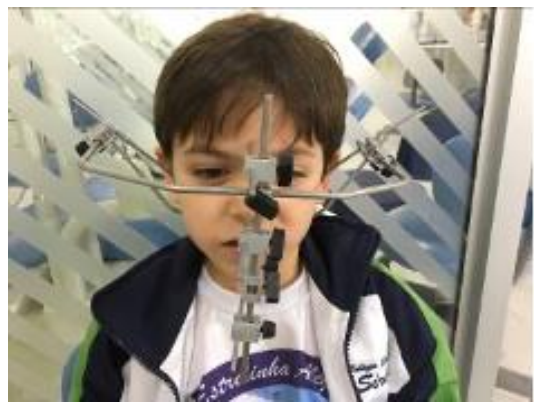

a)

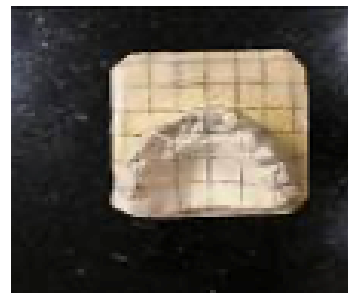

b)

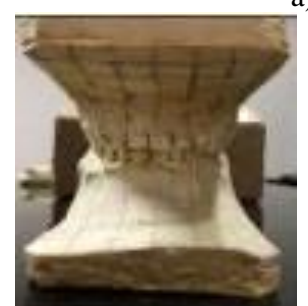

c)

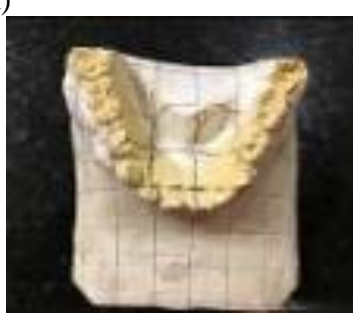

d)

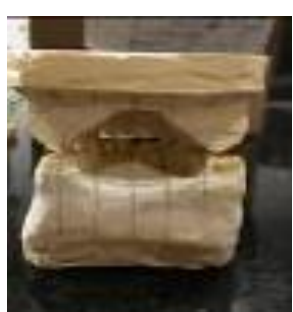

e)

Fig. 2. Gnathostatic models made after six months from T0; a) Gnathostatic facial arch, and b), c), d) and e) Gnathostatic model on different sides and view

In the following clinical examination and masticatory assessment, remaining protrusive movements were still observed, along with defective laterality as the right-sided movement was notably limited. We manufactured canine-to-canine planas direct tracks to reduce this protrusive movement, which facilitated the anterior crossbite correction, correction of the midline deviation 
(initially left-oriented), and the inversion of the chewing side to the right (Fig. 4(a)).
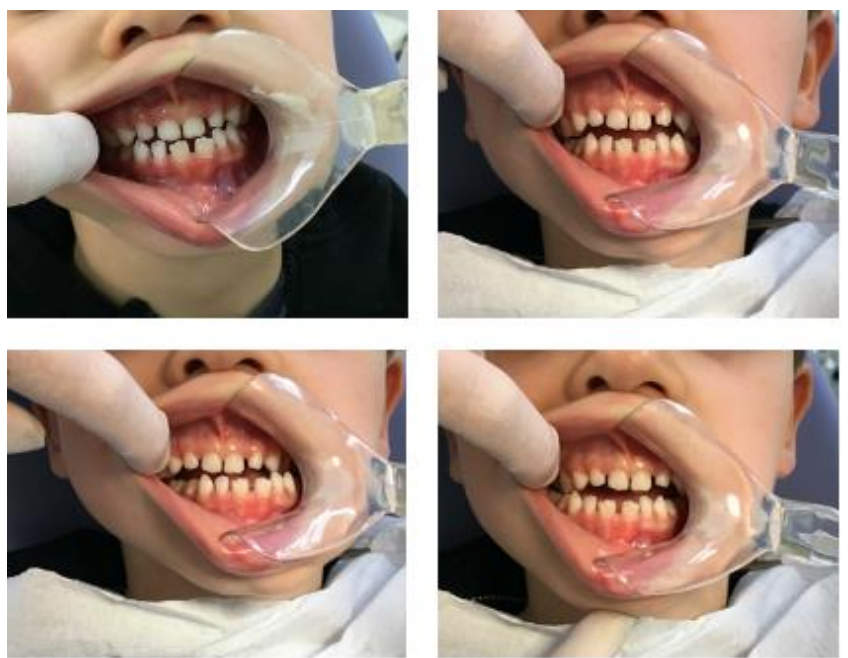

Fig. 3. Planas direct tracks installed in the occlusal surface of the upper and lower deciduous molars

Functional orthopedic treatment began four months after the treatment with the planas direct tracks, specifically with the Simões Network 3 (SN3) device, with Bimler's upper dental arch not touching the incisors and an upper expander. Furthermore, regarding the lower dental arch, we initiated the treatment with a Hawley dental device against the cervical third of lower incisors and a W-shaped lingual retainer (Fig. 4(b)). After six months of using the SN3 dental appliance, a new resin-composite was developed on teeth 63 and 53, appropriately aligning the midline deviation previously diagnosed and improving lateral movements (Fig. 4(c)). After one year of follow-up, we reobtained radiographic, orthopedic, and lateral teleradiographic (with Bimler cephalometric analysis) assessments to evaluate overall facial bone structure (Fig. 5). It is noteworthy a vertical facial growth, reduction of the saddle nose (commonplace characteristic of microrrinic dysplasia), and change in the anterior facial profile, converted from concave to convex. In addition, the suborbital facial index increased, which allowed the modification of the facial pattern from dolicoprosope to mesoprosope; thus, increasing the facial height and the vertical dimension.
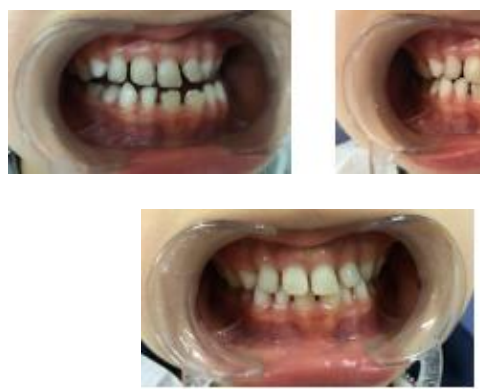

b)
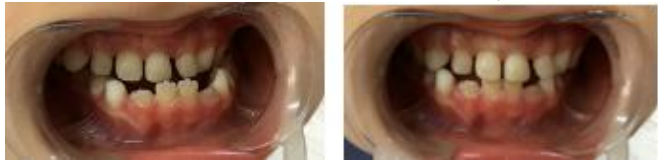

c)

a)
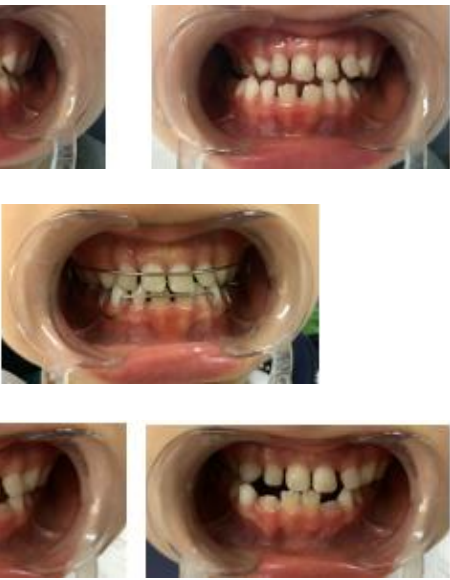

Fig. 4. a) Resin-composite planas direct tracks bonded directly to anterior teeth;

b) Simões Network 3 (SN3) appliances with Bimler's upper dental arch;

c) Second resin-composite planas direct tracks bonded to teeth \#63 and \#53 


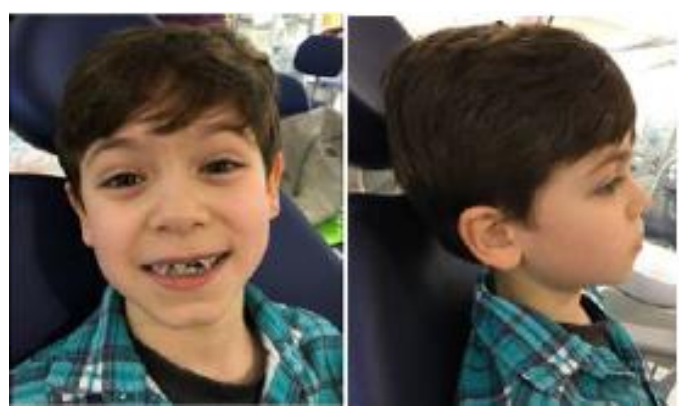

a)

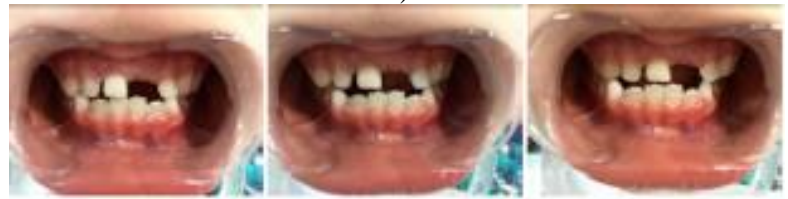

b)

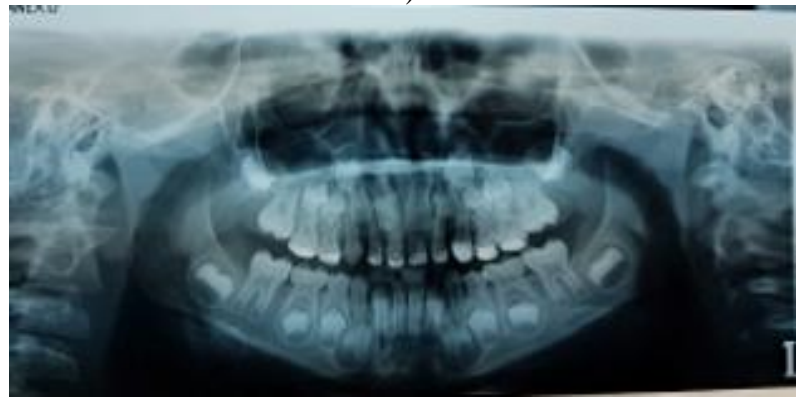

c)

Fig. 5. a) Extraoral photographs (T1), b) intraoral photographs (T1), and c) orthopantomogram (T1); $\mathrm{T} 1$ refers to the treatment stage after a one-year follow-up
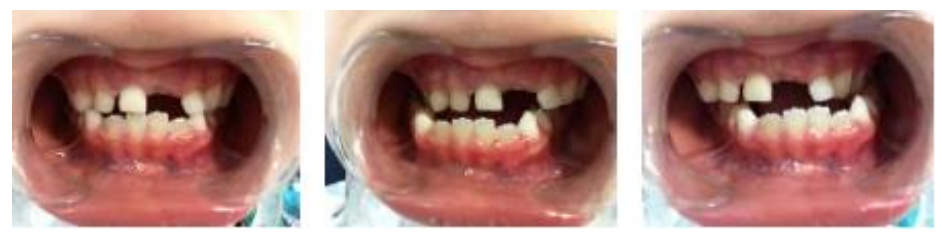

a)
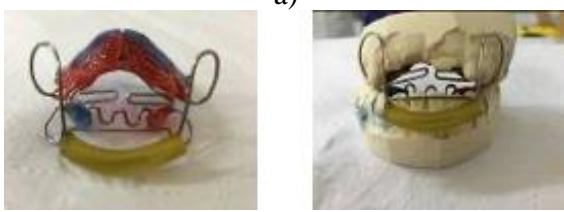

b)
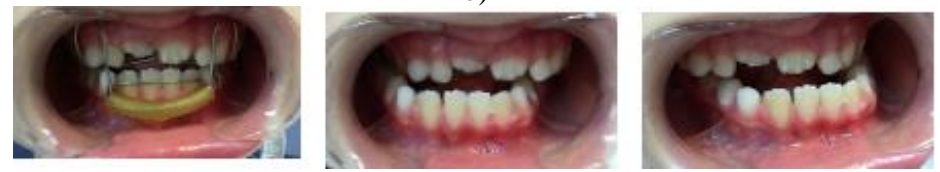

c)

Fig. 6. Patient with second SN3 oral appliances and intraoral photographs after one-year follow-up

The T-TM distance was enhanced from $25 \mathrm{~mm}$ to $27 \mathrm{~mm}$. Therefore, by managing the initial diagnosis of Class I malocclusion (pseudo-class III), the anterior crossbite was corrected, evidenced by the overlapping of the upper incisor under the lower incisor, which permits the 
redirection of mandibular growth. We observed that the left mandibular body was longer than expected in the subsequent panoramic radiograph due to the contralateral masticatory stimulus (Fig. 5). Table 2, section B evidences the values of referred anatomical structures (right and left sides) in the second panoramic radiography. At the same period, a second gnathostatic model was created using the facial arch.

Following one year of functional orthopedic treatment with planas direct track associated with the use of the SN3 device (adjusted monthly for eight months), the patient had a symmetrical occlusal plane, with the mandible centered on the gnathostatic cube (distally reaching both mandibular and maxillary canines), and a bilateral uniformity. Moreover, due to the patient's accelerated stage of development and, it was necessary to replace the functional orthopedic device with a new SN3 with progeny arch, active front spring, upper median expander, W-shaped bar, and lower vestibular arch. The progeny arch was needed to inhibit the mandibular growth and the front springs from stimulating the anterior maxilla's segment (Fig. 6).

After a two-year follow-up period, final clinical, orthopedic, and radiographic registries were carried out (Fig. 7). Cephalometric assessment at that point revealed positive structural changes ( $<$ A and positive A'B', mesoprosope biotype, meso suborbital facial index biotype, and more considerable T-TM distance) (Fig. 7 and Table 1, Column C). The patient presented with a centralized midline, a balanced maxillomandibular growth, and had central incisors in a physiologically determined area (with $2 \mathrm{~mm}$ overlap) (Fig. 8). Furthermore, the child could properly alternate bilateral chewing associated with adequate lateral movements. Comparative long-term cephalometric tracings and lateral radiographs (2017 to 2019) are shown in Fig. 9.
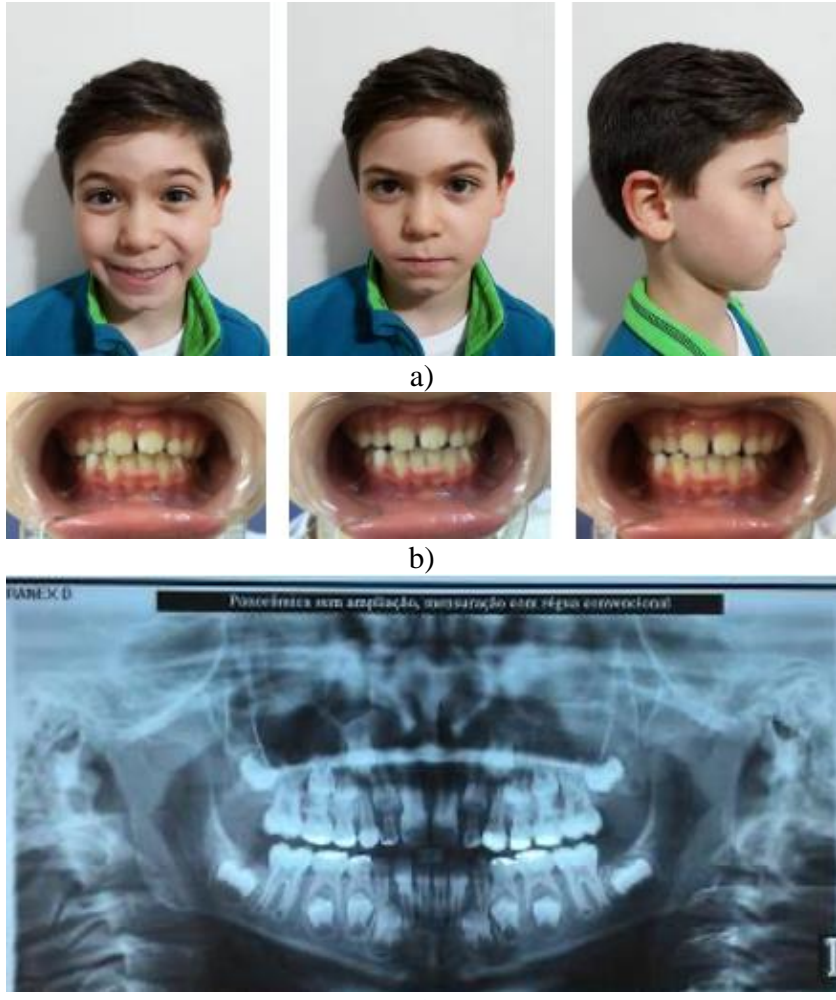

c)

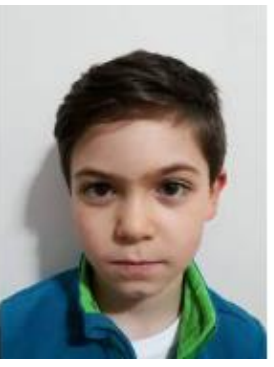

a)

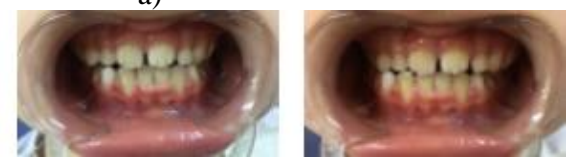

b)

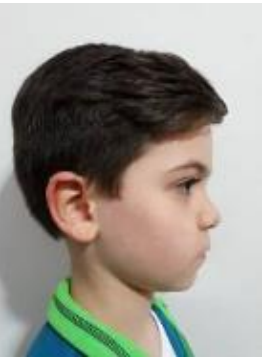

Fig. 7. a) Extraoral photographs (T2), b) intraoral photographs (T2), and c) orthopantomogram (T2); T2 refers to the post-treatment stage 

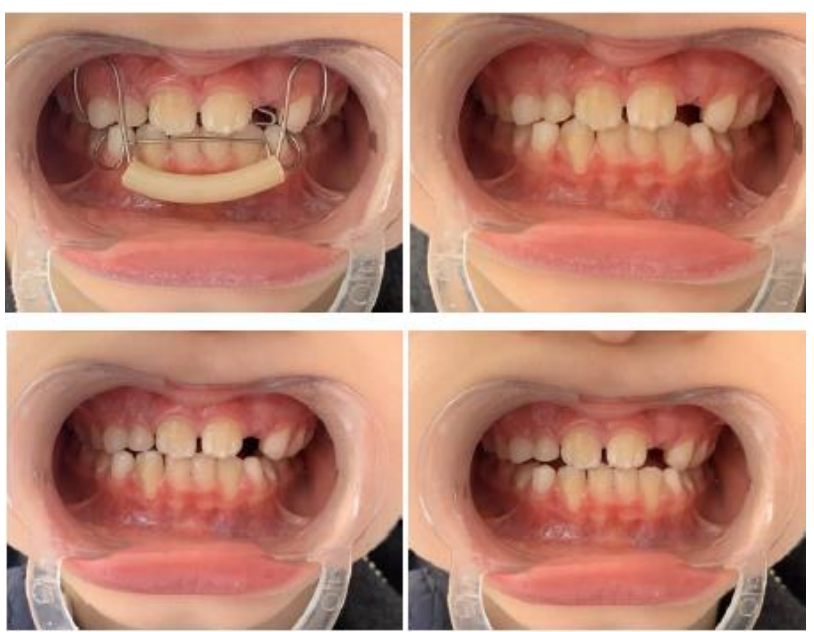

Fig. 8. Extraoral photographs (T2); T2 refers to the post-treatment stage

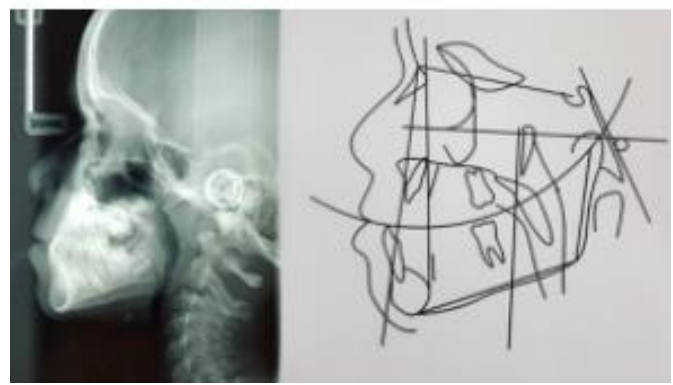

a)
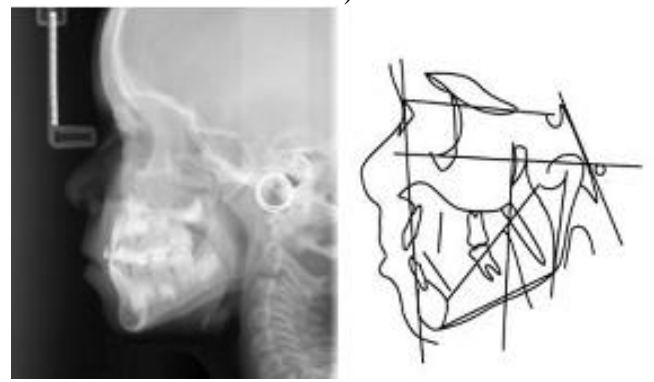

b)
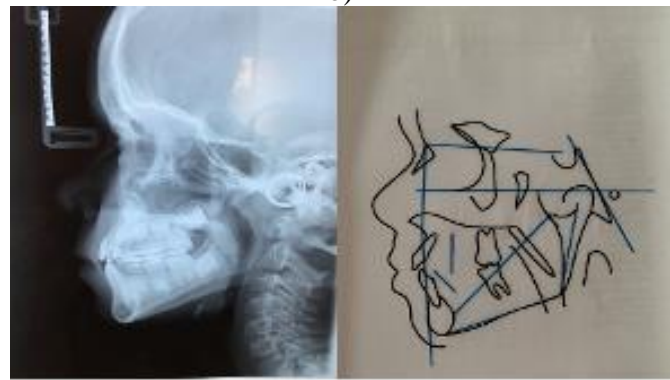

c)

Fig. 9. a) Lateral teleradiograph and cephalometric analysis in 2017; b) lateral teleradiograph and cephalometric analysis in 2018; c) lateral teleradiograph and cephalometric analysis in 2019 


\section{Discussion}

Access to dental care services - even in high-income countries - is a significant concern that affects all aspects of healthcare. Thus, early recognition of oral-related problems is critical to avoid further systemic consequences. This case report illustrates features associated with the early delivery of orthodontic treatment, showing the benefits and intermediate results of the treatment during primary and mixed dentition. However, as initially stressed by the patient's mother, several orthodontists and dental specialists still believe that later, single-phase treatment is more effective.

The foundations of biology, built-in terms of elements, logic, and principles associated with our presented features of growth and development suggest that most cases of malocclusions and facial deformities are worsened with age [10]. The capability of cells, tissues, and organs to adapt via normal growth processes is greatest early in development and diminishes as maturation is approached. Early treatment of anterior crossbite offers a favorable prognosis, significantly impacting patients' quality of life. Considering the impact of early delivery of care, it is essential to perform a correct diagnosis to differentiate a crossbite primarily cause by a postural alteration of the mandible from those resulting from an inordinate growth of bone bases in the sagittal plane [11]. Among the recommended differential diagnosis protocols available, one of them compares the patient's normal occlusion with the occlusion resulting from mandibular manipulation, leading the condyles to a centric relationship [11].

According to Ge et al. [12], the anterior crossbite may correct itself during primary or mixed dentition, but in some cases, it might persist or worsen for a more extended period. There is a consensus in the literature around the fact that the spontaneous resolution of malocclusion is improbable and that once established during the primary dentition phase, it must be perpetuated in the permanent dentition phase [11], [13]. Therefore, it is crucial that parents, dentists, physicians, and healthcare professionals recognize parafunctional oral habits and structure disorders to establish an adequate diagnosis and deliver an early intervention.

Identifying neurophysiological mechanisms involved in the craniofacial growth and development process and recognizing environmental factors that might affect these mechanisms scientifically substantiated the art of jaw functional orthopedics in promoting or restricting growth and changes in skeletal direction and posture [14]. Neurocclusal rehabilitation assesses the etiology of functional disorders of the stomatognathic system and considers multiple life expositions, starting in breastfeeding and extending to senility. Nevertheless, because the stimulation is frequently pathological, we perceive functional lesions since primary dentition.

Over the past few years, a wide variety of treatment alternatives have become available, depending on the patient's clinical conditions, the time needed for treatment, patient's and parent's cooperation, and features associated with costs and executability of dental appliances. More recently, the use of planas direct tracks to correct anterior and posterior crossbite in primary dentition has become more frequent, which can easily manage these oral deformities if diagnosed prematurely [15]. The planas direct tracks are prism-shaped blocks incorporating inclined planes made up of composite resin directly built or cemented on the occlusal surface of deciduous molars. The device is designed such that the distal incline of upper blocks occludes with the mesial angle of lower blocks so that mandible will have a posterior path of closure and condyles in centric relation. Interestingly, if kept untreated for long, it can lead to physiological, social, and psychological disorders, sometimes irreversible [16]. Initially, the planas direct tracks were adapted to correct the anterior and posterior crossbite [17]-[19]. Subsequently, Simões suggested that these orthodontic devices should be used only in deciduous dentition covering the molar's occlusal surface [20]. Thus, our treated patient would achieve the normalization of dental occlusion, mandibular posture, condylar position, and masticatory function by adhering to this protocol until the molar's eruption.

Pseudo-class III malocclusion is characterized by the deviation of maxillary and mandibular growth patterns, with a discrepancy between the centric and occlusal relationships. As the planas direct tracks treatment relies upon the inclined plane technique, it corrects the displacement of the 
centric and occlusal relationship by pressing the mandible downwards. Different treatment approaches for the anterior crossbite correction can be used during the initial period of mixed dentition. Some appliances improve malocclusion by changing the inclination of the upper and lower incisors, while others, by opening the bite (using a reverse twin block appliance). However, these traditional oral appliances are bulky, exert excessive pressure, and require patient compliance to the treatment [21], [22]. Considering these aspects, planas direct tracks made up of composite resin were the treatment of choice to correct anterior crossbite (pseudo-class III) due to its low cost and technical simplicity. It is worth mentioning that these oral appliances do not require unique material or equipment for construction and do not rely on patient's collaboration because they are based on "adhesive restorations" and selective wear that remain active in the stomatognathic system 24 hours a day [18]. In the study developed by Devasya et al., the planas direct tracks were fabricated using self-cure acrylic resin to reduce a two-step laboratory procedure to a single-step process, which minimizes the fabrication complexity, decreases the consultation time, and improves patient's collaboration [23].

Notably, in centric occlusion, the condyles are located concentrically in the glenoid fossae. However, as far as patients with crossbite are concerned, the same pattern is not observed as there is a muscle imbalance associated with displacement and abnormalities of the temporomandibular joint. The planas direct tracks act by repositioning the mandible and modifying the temporomandibular joint, placing the condyles in a posterior position. Due to the continuous growth, the temporomandibular components such as the glenoid fossae, ligaments, and joint space, accommodate and modify the new position of growing condyles. This hinders establishing morphological and positional asymmetries among children in the deciduous dentition phase, enabling better and balanced craniofacial growth [15].

The functional orthopedic appliance SN3 functions to change the mandibular growth rotation, fostering a change in the maxillomandibular posture. The lateral pterygoid, digastric, and styloglossus muscles, when stimulated, modulate the bones and adequately place the teeth in the arch [20]. The SN3 dental appliance was used for one year and eight months and monthly adjusted in this study.

In the clinical case presented, significantly positive results were achieved using the planas direct tracks and the functional orthopedic appliance SN3 following a one-year treatment plan. Relevant outcomes include achieving symmetry of the occlusal plane, distal canine tangency, and bilateral uniformity, which reestablished the harmonic occlusal pattern and restructured the stomatognathic system morphology. Similar results were reported by Gabin et al., who associated the favorable prognosis mainly due to planas direct track's action in determining a correct excitation and stimulation in the neural centers [24]. More specifically, this is established because of its effect in restructuring the functional occlusion pattern by balancing neuromuscular activity, reflecting the good development of cranial muscle structures. Additionally, several studies have proposed using planas direct tracks as an efficient intervention for the early correction of pseudo-class III malocclusion [10]. Future long follow-up studies with a better study design and a more representative number of patients are still needed to understand the effects of planas direct tracks in bone morphology and soft tissues.

\section{Conclusions}

The case report highlights the importance of early orthodontic treatment and shows significant dental occlusion and masticatory performance improvement. Functional jaw orthopedics contributes significantly to stimulating facial structures and establishes a harmonic development of the stomatognathic system, particularly among patients in mixed dentition diagnosed with an anterior crossbite. 


\section{References}

[1] G. Farronato, L. Giannini, G. Galbiati, and C. Maspero, "Sagittal and vertical effects of rapid maxillary expansion in Class I, II, and III occlusions," The Angle Orthodontist, Vol. 81, No. 2, pp. 298-303, Mar. 2011, https://doi.org/10.2319/050410-241.1

[2] F. Falck and K. Zimmermann-Menzel, "Cephalometric changes in the treatment of class III using the Fränkel appliance," Journal of Orofacial Orthopedics / Fortschritte der Kieferorthopädie, Vol. 69, No. 2, pp. 99-109, Mar. 2008, https://doi.org/10.1007/s00056-008-0716-7

[3] Rodrigo Hermont Cançado, José Fernando Castanha Henriques, Cíntia Maria de Souza E. Silva, Leniana Santos Neves, and Marcos Roberto de Freitas, "Intervenção não-cirúrgica da má oclusão de Classe III: quando e como tratá-la?," (in Portuguese), Revista Clínica de Ortodontia Dental Press, Vol. 4, No. 6, pp. 46-55, Dec. 2005.

[4] F. Borrie and D. Bearn, "Early correction of anterior crossbites: a systematic review," Journal of Orthodontics, Vol. 38, No. 3, pp. 175-184, Sep. 2011, https://doi.org/10.1179/14653121141443

[5] Wong Ml, Che Fatimah Awang None, Ng Lk, Norlian D., Rashidah Dato Burhanudin None, and Gere $\mathrm{Mj}$, "Role of interceptive orthodontics in early mixed dentition," Singapore Dental Journal, Vol. 26, No. 1, pp. 10-14, Dec. 2004.

[6] M. K. Väkiparta, H. M. Kerosuo, M. E. Nyström, and K. A.-K. Heikinheimo, "Orthodontic treatment need from eight to 12 years of age in an early treatment oriented public health care system: a prospective study," The Angle Orthodontist, Vol. 75, No. 3, pp. 344-349, May 2005, https://doi.org/10.1043/0003-3219(2005)75

[7] I. S. H. Navarrete and A. T. Jiménez, "Functional maxillary orthopedics in early treatment of class II malocclusions due to mandibular retrusion: Case report," Universidad Nacional Autonoma de Mexico, Revista Mexicana de Ortodoncia, Jul. 2017.

[8] T. Baccetti, D. Rey, G. Oberti, F. Stahl, and J. A. Mcnamara, "Long-term outcomes of Class III treatment with mandibular cervical headgear followed by fixed appliances," The Angle Orthodontist, Vol. 79, No. 5, pp. 828-834, Sep. 2009, https://doi.org/10.2319/111408-580.1

[9] A.-P. Wiedel and L. Bondemark, "Fixed versus removable orthodontic appliances to correct anterior crossbite in the mixed dentition - a randomized controlled trial," The European Journal of Orthodontics, Vol. 37, No. 2, pp. 123-127, Apr. 2015, https://doi.org/10.1093/ejo/cju005

[10] K. Vora, A. Misal, and N. Toshniwal, "An innovative approach for correction of pseudo class III malocclusion with the use of "Planas direct tracks", APOS Trends in Orthodontics, Vol. 3, No. 6, p. 190, 2013, https://doi.org/10.4103/2321-1407.121440

[11] L. B. Rossi, K. E. D. C. Pizzol, E. M. Boeck, N. Lunardi, and A. J. I. Garbin, "Correção de mordida cruzada anterior funcional com a Terapia de Pistas Diretas Planas: Relato de Caso," (in Portuguese), Revista da Faculdade de Odontologia de Lins, Vol. 22, No. 2, pp. 45-50, Dec. 2012, https://doi.org/10.15600/2238-1236/fol.v22n2p45-50

[12] Y. Ge, J. Liu, X. Guo, and J. Han, "A follow-up study of early interceptive treatment of primary anterior crossbites," The European Journal of Orthodontics, Vol. 33, No. 5, pp. 551-557, Oct. 2011, https://doi.org/10.1093/ejo/cjq120

[13] T. I. L. Zózimo, G. R. P. Santos, and J. V. B. S. Silva, "Correção de mordida cruzada anterior funcional com pistas diretas planas: relato de caso clínico," (in Portuguese), Archives of Health Investigation, Vol. 7, Oct. 2018

[14] M. A. Rezende, "SOS Respirador bucal: uma visão funcional e clínica da amamentação," (in Portuguese), Revista Latino-Americana de Enfermagem, Vol. 12, No. 1, pp. 139-139, Feb. 2004, https://doi.org/10.1590/s0104-11692004000100020

[15] P. Planas, Rehabilitation Neuro Occlusal. Spain: Masson-Salvat Odontologia Barcelona, 1994.

[16] L. Dimberg, K. Arnrup, and L. Bondemark, "The impact of malocclusion on the quality of life among children and adolescents: a systematic review of quantitative studies," The European Journal of Orthodontics, Vol. 37, No. 3, pp. 238-247, Jun. 2015, https://doi.org/10.1093/ejo/cju046

[17] Ramirez-Yañez Go, "Planas direct tracks for early crossbite correction," Journal of Clinical Orthodontics: JCO, Vol. 37, No. 6, pp. 294-298, Jun. 2003.

[18] A. C. R. Chibinski, G. D. Czlusniak, and M. D. Melo, "Pistas diretas planas: terapia ortopédica para correção de mordida cruzada funcional," (in Portuguese), Revista Clínica de Ortodontia Dental Press, pp. 64-72, 2005. 
[19] R. R. D. Santos, A. J. Isper Garbin, and C. A. Saliba Garbin, "Early correction of malocclusion using planas direct tracks," Case Reports in Dentistry, Vol. 2013, p. 395784, 2013, https://doi.org/10.1155/2013/395784

[20] W. A. Simões, "Selective grinding and Planas' direct tracks as a source of prevention," The Journal of Pedodontics, Vol. 5, No. 4, pp. 298-314, 1981.

[21] Turley P. K., "Orthopedic correction of Class III malocclusion with palatal expansion and custom protraction headgear," Journal of Clinical Orthodontics: JCO, Vol. 22, No. 5, pp. 314-325, May 1988.

[22] Mcnamara Ja, "An orthopedic approach to the treatment of Class III malocclusion in young patients," Journal of Clinical Orthodontics: JCO, Vol. 21, No. 9, pp. 598-608, Sep. 1987.

[23] A. Devasya, N. K. Ramagoni, M. Taranath, K. E. Prasad, and M. Sarpangala, "Acrylic planas direct tracks for anterior crossbite correction in primary dentition," International Journal of Clinical Pediatric Dentistry, Vol. 10, No. 4, pp. 399-403, Dec. 2017, https://doi.org/10.5005/jp-journals10005-1473

[24] A. J. I. Garbin, B. Wakayama, T. A. S. Rovida, and C. A. S. Garbin, "A utilização da Pista Direta de Planas no tratamento precoce da mordida cruzada posterior: relato de caso," (in Portuguese), Archives of Health Investigation, Vol. 5, No. 4, p. 2016, Sep. 2016, https://doi.org/10.21270/archi.v5i4.1326

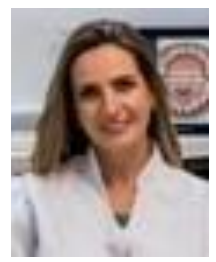

Fabiana Monte Callado received a Bachelor's degree in Dentistry in 2002 at the Universidade de Santo Amaro, Santo Amaro, São Paulo, Brazil. She is a specialist in orthodontics and functional jaw orthopedics. Currently, she has been engaged in private clinical practice, mainly assisting pediatric patients at the Clínica for U Odontologia Especializada, São Paulo, São Paulo, Brazil.

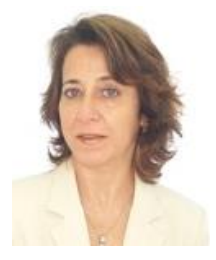

Maria Luiza Sperandeo received a Doctorate and post-doctorate at the Universidade Estadual de Campinas, Campinas, São Paulo - Brazil. She is a specialist in Functional Jaw Orthopedics and Pediatric Dentistry. She has a comprehensive experience with physiology, focusing her research on learning, neural plasticity, and neurosciences. Currently, she is the coordinator of the Functional Jaw Orthopedics course at FAPES. She co-authored popular books, including "Functional and Molecular Orthopedics Based on Neurophysiology" (2013). 